\title{
Theoretical Study of Anomalously High $F$ Region Peak Altitudes in the Polar Ionosphere
}

\author{
J. J. SOJKA AND R. W. SCHUNK
}

Center for Atmospheric and Space Sciences, Utah State University, Logan

\begin{abstract}
During the last solar maximum period several observations of anomalously high $F$ region peak altitudes have been made by the high latitude incoherent scatter radars. The observations indicate that there are several distinctive features associated with these high $h_{m} F_{2}$ ionospheric profiles: (1) they are observed near midnight with the plasma flowing out of the polar cap, (2) $N_{m} F_{2}$ ranges from $10^{5}$ to $10^{6} \mathrm{~cm}^{-3}$, (3) $h_{m} F_{2}$ ranges from 400 to $500 \mathrm{~km}$, (4) below $300 \mathrm{~km}$ the profile is devoid of ionization, and (5) the observations are for solar maximum conditions. In an effort to explain these radar observations, a time-dependent high latitude ionospheric model was used to study transport effects for a wide range of solar cycle, seasonal, magnetic activity, and neutral wind conditions. The model results indicate that high $h_{m} F_{2}$ values in the midnight sector of the polar region can be generated without the need for ionization due to auroral precipitation. For solar maximum, all of the observed features of the high $h_{m} F_{2}$ density profiles are reproduced by the model if the neutral wind across the polar cap is greater than $400 \mathrm{~m} / \mathrm{s}$. Such wind speeds have been frequently measured during the last solar maximum period. The study also shows general results for the influence of transport in the polar cap for different seasonal and solar cycle conditions. $N_{m} F_{2}$ and $h_{m} F_{2}$ are lower for solar minimum than solar maximum. However, the seasonal dependences are strongly coupled with both the strength of the convection and the neutral wind speed.
\end{abstract}

\section{INTRODUCTION}

During the last solar maximum period several observations of anomalously high $F$ region peak altitudes $\left(h_{m} F_{2}\right)$ have been made by the high latitude incoherent scatter radars. These observations were typically made in the midnight sector at latitudes poleward of the auroral oval, where the plasma generally convects in an antisunward direction (private communications, J. Foster, 1983, and V. Wickwar, 1983). The high $F$ region peaks observed were in the range of 400 to $500 \mathrm{~km}$, while the corresponding peak densities were in the range $10^{5}$ to $10^{6} \mathrm{~cm}^{-3}$. A feature characteristic of these anomalously high $h_{m} F_{2}$ 's is that below the peak the density decreased extremely rapidly, indicating an almost complete absence of a bottomside $F$ region and $E$ region.

Figure 1 shows one of the few published examples of an anomalously high $F$ region peak [from Murdin et al., 1984]. This figure shows the $N_{e}$ density variation at eight altitudes above the Chatanika incoherent scatter radar over a 68 -hour period starting at 0000 UT on April 12, 1978. These data were obtained when the Chatanika incoherent scatter radar operated in a high resolution, local mode. Three vertical lines divide the data into periods of differing magnetic activity, as labeled on the figure. To the right of each line is the local midnight sector. The first and third of these regions show relatively low densities with the highest densities occurring in the 110 - to $160-\mathrm{km}$ altitude range. No clear $F$ region feature is present. In contrast, the second midnight sector, which follows a "quiet" day, shows a very distinct high $h_{m} F_{2}$ signature. The density increases with altitude, reaching a peak at about $410 \mathrm{~km}$ of $N_{m} F_{2} \sim 3 \times 10^{5} \mathrm{~cm}^{-3}$. This peak is not only very high, but is also $\sim 10 \%$. At since at $460 \mathrm{~km}$ the density has only decreased by $\sim 10 \%$. At the time of this midnight observation the other radar Chatanitions indicated the plasma was flowing antisunward toward wind wa and that a significant upward drift induced by the neutral was was present [Murdin et al., 1984]. A weak $E$ region feature was also present (see $N_{e}$ at $110 \mathrm{~km}$ ). This high $h_{m} F_{2}$ remained for

\footnotetext{
Copyright 1985 by the American Geophysical Union

Paper number 4A8420.
$0148-0227 / 85 / 004 \mathrm{~A}-8420 \$ 05.00$
}

about 3 hours, and then the $F$ region returned to a more normal shape with an $h_{m} F_{2}$ of about $350 \mathrm{~km}$.

In this investigation we used our high latitude time-dependent $F$ region model (HLTD) [Sojka et al., 1979, 1981a, b; Sojka and Schunk, 1984] to study a range of differing plasma transport processes in order to identify possible source mechanisms for these anomalously high $h_{m} F_{2}$ 's. Since the observations are consistent with the idea that the plasma flows antisunward across the polar cap toward midnight, we assumed that the plasma flux tube originates somewhere on the dayside under well-defined solar EUV conditions. The HLTD model then determined how the flux tube was transported across the polar cap to the point of observation. For this study we assumed that the only plasma sources were solar EUV radiation and resonantly scattered radiation. Ionization produced by particle precipitation was deliberately excluded from this study in order to determine the effectiveness of transport processes in producing high $h_{m} F_{2}$ values. Also, the radar observations described above indicated that the high $h_{m} F_{2}$ profiles had a marked absence of ionization below the $F$ region peak, suggesting that local particle precipitation was absent. The effects of hard and soft auroral precipitation will be discussed in a separate study.

Transport processes were considered because vertical drifts induced by either $\mathbf{E} \times \mathbf{B}$ forces or a neutral wind have been shown to be effective in raising and lowering the $F$ region peak (see, for example, Banks and Kockarts [1973]). In this regard, it should be noted that the local evolution of the auroral $N_{e}$ profile for various neutral wind speeds was studied by Watkins and Richards [1979]. Under local auroral conditions the effect of the equatorward neutral wind was to raise the $F$ region peak. However, since $\mathbf{E} \times \mathbf{B}$ transport was not included in that study, the full consequences of the transport processes were not shown.

Several parameters, covering solar cycle and seasonal conditions as well as magnetospheric electric field and neutral wind conditions, were varied systematically as inputs to the HLTD model. This wide range of different transport conditions covers the expected high latitude ionospheric transport conditions and will indicate to what extent these processes can produce the anomalously high $h_{m} F_{2}$ values observed. In the following section these input parameters are described in detail. 


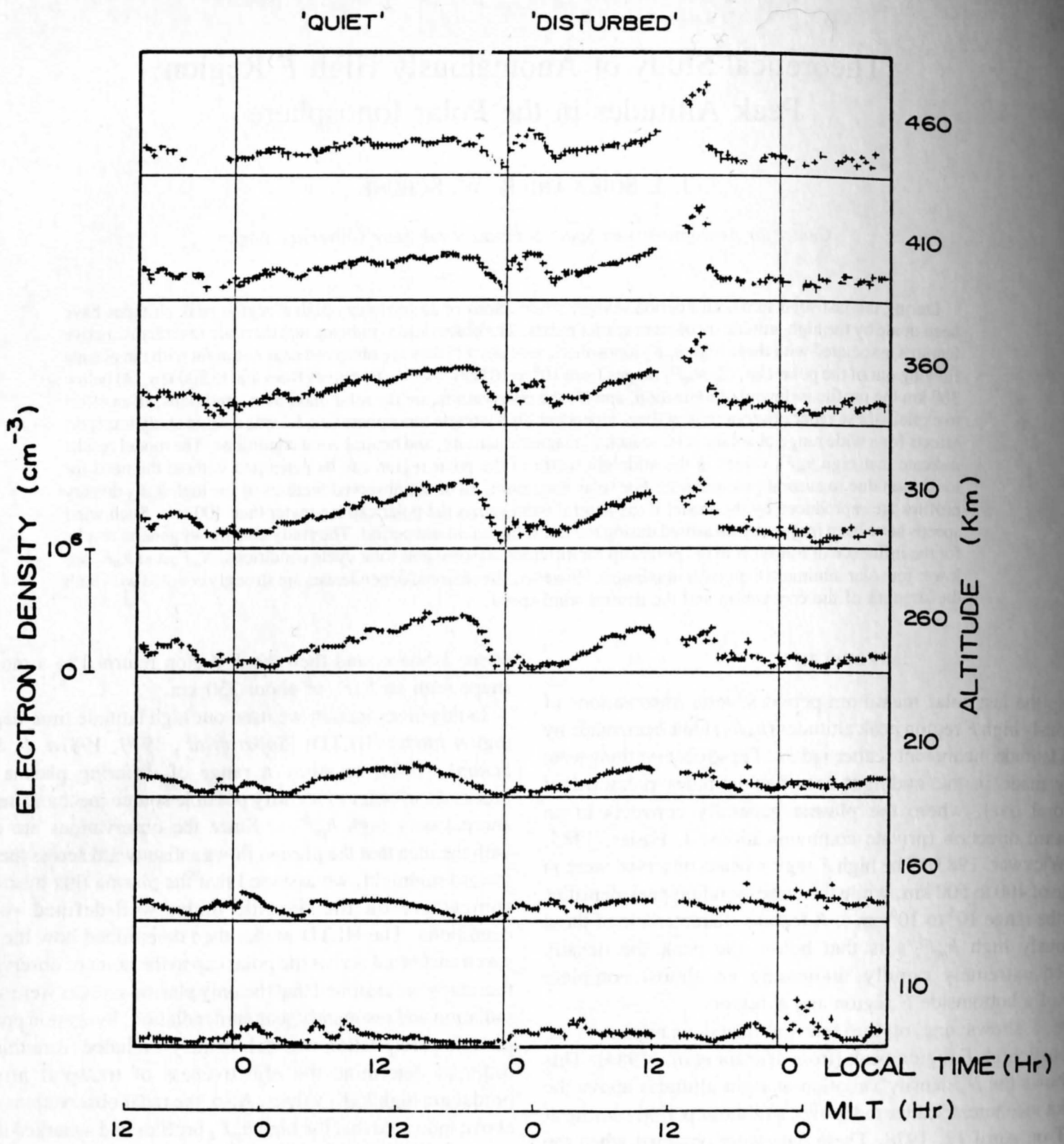

Fig. 1. Observed Chatanika radar electron densities at eight altitudes over a 68-hour period [from Murdin et al., 1984].

\section{Model PARAMETERS}

The $F$ region plasma observed poleward of the midnight auroral oval has been transported to this location from a point on the dayside. The speed of this transport process depends primarily on the polar cap electric field strength. Figure 2 shows two trajectories which transport plasma from the same dayside (sunlit) location across the polar cap to the midnight sector for two different polar cap electric field strengths. The left panel corresponds to extremely quiet magnetic conditions with a cross-polar cap potential of $7 \mathrm{kV}$. In this case the plasma takes 14.4 hours to convect to the midnight meridian. In contrast, the right panel is for more active magnetic conditions, with a polar cap potential drop of $56 \mathrm{kV}$, and the convection time to midnight is only 3.6 hours.

For both panels a symmetric Volland magnetospheric convection model has been used [Volland, 1978]. The plasma following the flux tube shown in the left panel primarily corotates once it enters the polar cap, the corotational speed being $124 \mathrm{~m} / \mathrm{s}$. In contrast the
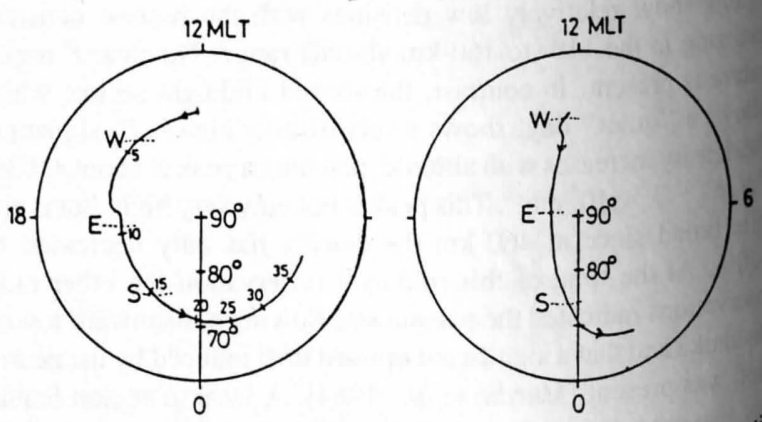

Fig. 2. The slow (left panel) and fast (right panel) plasma convection trajectories used in this study plotted in an MLT (magnetic latitude) frami The dashed lines marked W, E, and S represent the solar terminator locatio for winter, equinox, and summer, respectively. 

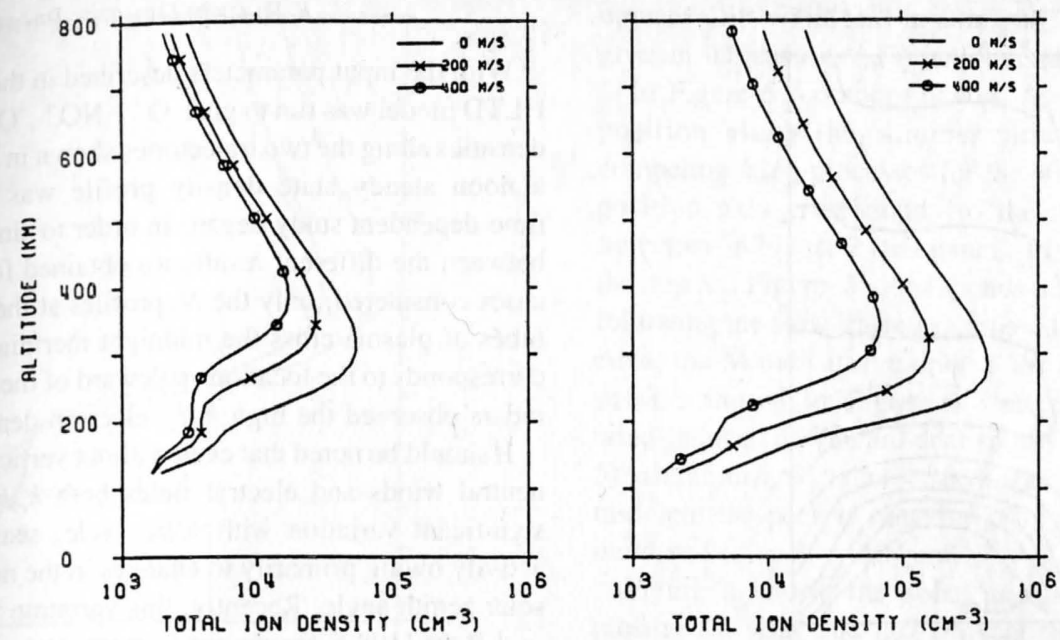

Fig. 3. Midnight $N_{e}$ profiles at solar maximum, winter, for slow convection (left panel) and fast convection (right panel). Each panel shows three $N_{e}$ profiles corresponding to three different neutral wind speeds, as indicated in the key.

plasma following the flux tube shown in the right panel convects across the polar cap with a speed dominated by the $\mathbf{E} \times \mathbf{B}$ drift, which is $420 \mathrm{~m} / \mathrm{s}$. Since these two trajectories are compared throughout the following text, the magnetospheric conditions associated with the left and right panels will be referred to as "slow convection" and "fast convection," respectively. Note that the two trajectories pass through different regions. The slow convection trajectory lies close to the poleward auroral boundary in the afternoon sector, whereas the fast trajectory cuts straight across the polar cap. Although the trajectories convect through different regions of the polar cap, neither enters the auroral oval until they get around to midnight. Therefore, auroral precipitation was not included along any part of the two trajectories. The consequences of precipitation will be discussed later.

The magnetospheric electric field not only produces the horizontal $\mathbf{E} \times \mathbf{B}$ velocity, which together with corotation produces the trajectories shown in Figure 2, but also produces a vertical $\mathbf{E} \times$ B plasma drift. This vertical drift depends on the magnetic field dip angle, which leads to vertical drifts up to $35 \mathrm{~m} / \mathrm{s}$ for the fast convection trajectory. These drifts drive plasma upward on the dayside and downward on the nightside. For the slow convection case, the maximum vertical drift is small, only $4 \mathrm{~m} / \mathrm{s}$, since the flux tube is primarily corotating.

An additional vertical drift is induced by the presence of a cross-polar cap neutral wind. For this study the neutral wind was assumed to blow from 1300 to $0100 \mathrm{LT}$, with a constant speed everywhere [Murphy et al., 1976; Sojka et al., 1981b]. In the $F$ region this wind was assumed to be altitude independent. In general, three different wind strengths were considered: 0, 200, and $400 \mathrm{~m} / \mathrm{s}$. The $400-\mathrm{m} / \mathrm{s}$ neutral wind corresponds to vertical ion drifts up to $65 \mathrm{~m} / \mathrm{s}$. For solar maximum conditions with fast convection, an additional case with a neutral wind of $800 \mathrm{~m} / \mathrm{s}$ was considered. The induced vertical ion drifts were downward during the day and upward at night. The neutral wind-induced vertical drift was opposite to that of the $\mathbf{E} \times \mathbf{B}$ drift and acted as an important nighttime $F$ region maintenance mechanism.

The neutral atmosphere used in our model, MSIS [Hedin et al., 1977], requires the solar flux and $A p$ parameters. For this parametric study we chose two levels of solar flux, $F 10.7=70$ and 200, which are representative of solar minimum and solar maximum conditions, respectively. However, the $A p$ value was kept at 12 , since we ignored particle precipitation. Three seasonal
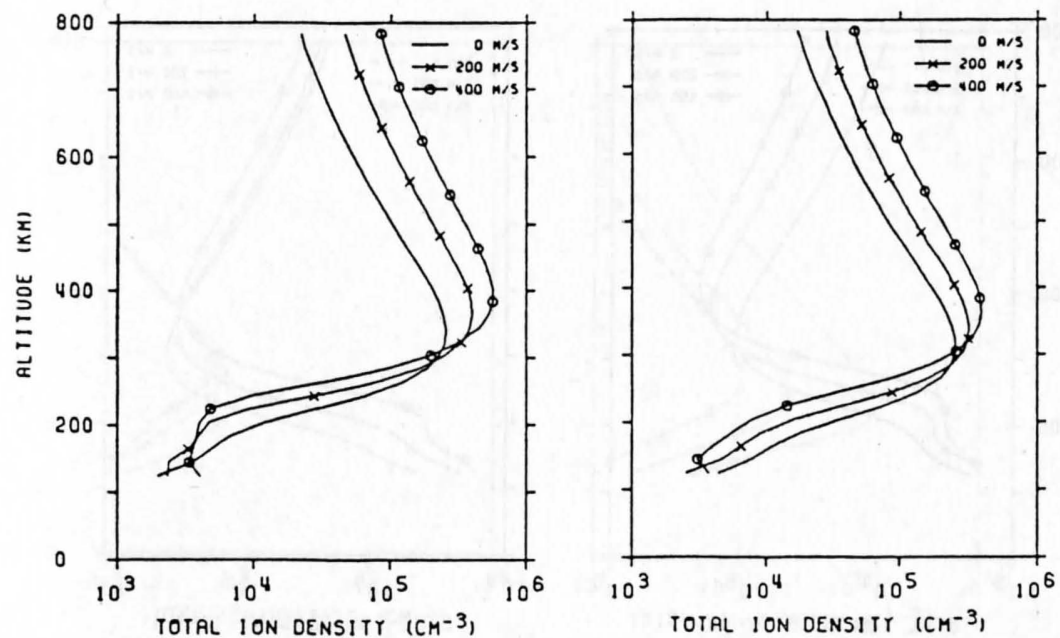

Fig. 4. Midnight $N_{e}$ profiles at solar maximum, summer, for slow convection (left panel) and fast convection (right panel). 


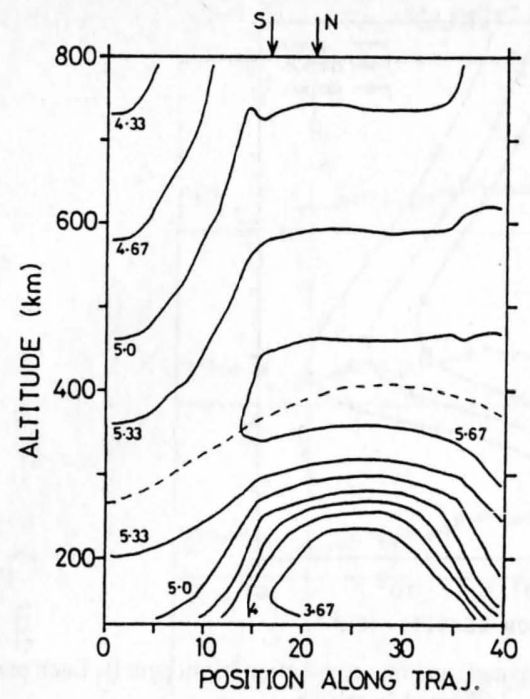

Fig. 5. Contours of $\log _{10}\left(N_{c}\right)$ as a function of altitude and position along the trajectory for slow convection and a $400-\mathrm{m} / \mathrm{s}$ neutral wind for solar maximum, summer conditions. The positions identified by numbers between 0 and 40 correspond to the tick marks shown in Figure 2, left panel.

conditions were selected, winter solstice, summer solstice, and equinox. In Figure 2 the dashed lines labeled W, S, and E indicate where the slow and fast convection trajectories cross the winter, summer, and equinox solar terminators, respectively. Since the location of the solar terminator is UT dependent in the magnetic frame, the UT start times for the slow and fast convection trajectories were chosen such that the plasma following the trajectories crosses the terminators at similar geometric locations relative to the 0600-1800 MLT meridian.

Our high latitude model also requires the electron temperature $T_{e}$ to be specified. For simplicity, we chose two $T_{e}$ profiles, one for the sunlit hemisphere and another for the dark hemisphere. The sunlit $T_{e}$ profile reaches $3200^{\circ} \mathrm{K}$ at $800 \mathrm{~km}$, while the dark $T_{e}$ profile only reaches $2200^{\circ} \mathrm{K}$ at $800 \mathrm{~km}$. These profiles are the same as used by Sojka et al. [1981 $a$ ]. The electron temperature is observed to be quite variable, especially under changing auroral conditions; however, since we ignored auroral precipitation, we did not attempt to let $T_{e}$ vary other than with the above day-night variation. This should not have an appreciable effect on our results, since $T_{e}$ does not strongly influence $h_{m} F_{2}$.

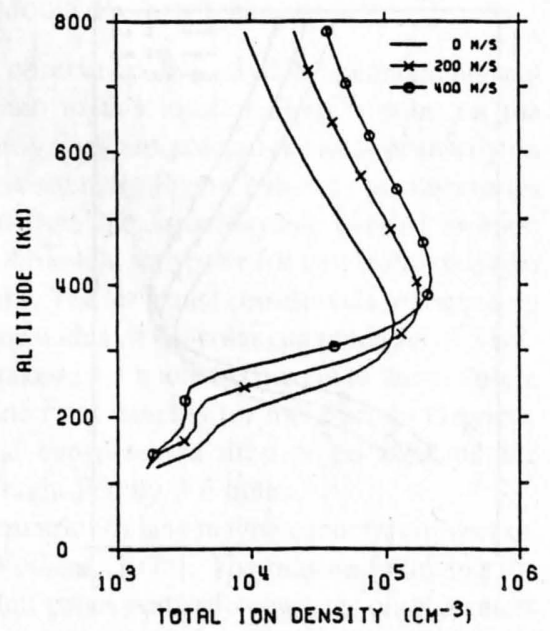

\section{$F$ REgION DENSITY PRofiLes}

With the input parameters described in the previous section,
LTD model was run to give $\mathrm{O}^{+}, \mathrm{NO}^{+}, \mathrm{O}_{2}^{+}, \mathrm{N}_{2}^{+}, \mathrm{N}^{+}$, and densities along the two trajectories shown in Figure $\mathrm{N}_{2}^{+}, \mathrm{N}^{+}$, and $\mathrm{He}_{\mathrm{e}}$ ' a noon steady state density profile was computed 2 . Foreach run, time-dependent study began. In order to simplify the before the between the different results we obtained for the large nurison: cases considered, only the $N_{e}$ profiles at the points where the of tubes of plasma cross the midnight meridian will be shown. fux corresponds to the locations poleward of the auroral oval where the radars observed the high $h_{m} F_{2}$ electron density profiles.

It should be noted that even without vertical ion drifts induced by neutral winds and electric fields both $h_{m} F_{2}$ and $N_{m} F_{2}$ exhibit significant variation with solar cycle, season, and geomagnetic activity owing primarily to changes in the neutral composition an solar zenith angle. Recently, this variation was studied by Schunt and Raitt [1980] for daytime steady state conditions, and it was shown that without induced vertical ion drifts, $N_{m} F_{2}$ can vary by more than an order of magnitude and $h_{m} F_{2}$ can vary by $100 \mathrm{~km}$ as the geophysical conditions are changed. Such variations are also evident in our results, but they will not be discussed in detail, since this already has been done by Schunk and Raitt [1980].

\section{Solar Maximum}

Figure 3 shows winter, midnight $N_{e}$ profiles for slow convection (left panel) and fast convection (right panel). In each panel the three profiles correspond to neutral wind speeds of 0,200 , and $400 \mathrm{~m} / \mathrm{s}$ flowing across the polar cap. For both slow and fast convection the effect of the neutral wind is to raise the $F$ peak, and thus increase $h_{m} F_{2}$. For slow convection, $h_{m} F_{2}$ reaches $400 \mathrm{~km}$ for the $400-\mathrm{m} / \mathrm{s}$ wind case, while the corresponding fast convection case has $h_{m} F_{2} \approx$ $350 \mathrm{~km}$. For fast convection the $\mathbf{E} \times \mathbf{B}$ induced downward drift competes with the wind-induced upward ion drift, causing the effective upward drift to be reduced and $h_{m} F_{2}$ to be lowered. For slow convection, $h_{m} F_{2}$ is raised by $\sim 100 \mathrm{~km}$ from $300 \mathrm{~km}$ to 400 $\mathrm{km}$ as the neutral wind increases from 0 to $400 \mathrm{~m} / \mathrm{s}$.

The slow convection densities are less than the corresponding fast convection densities. This arises because the plasma following the slow convection trajectory has been in darkness for almost 14.4 hours, while the plasma following the fast convection trajectory has been in darkness for only about 3.6 hours. Hence, the plasma following the slow trajectory has decayed significantly longer. Indeed, the decay of the topside has a time constant of the order of a

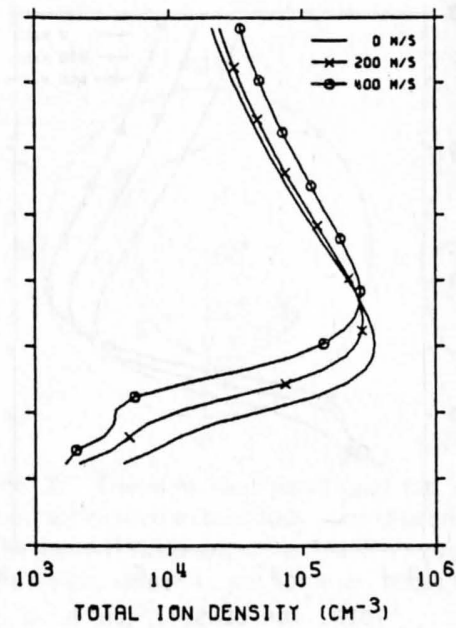

Fig. 6. Midnight $N_{c}$ profiles at solar maximum, equinox, for slow convection (left panel) and fast convection (right panel). 


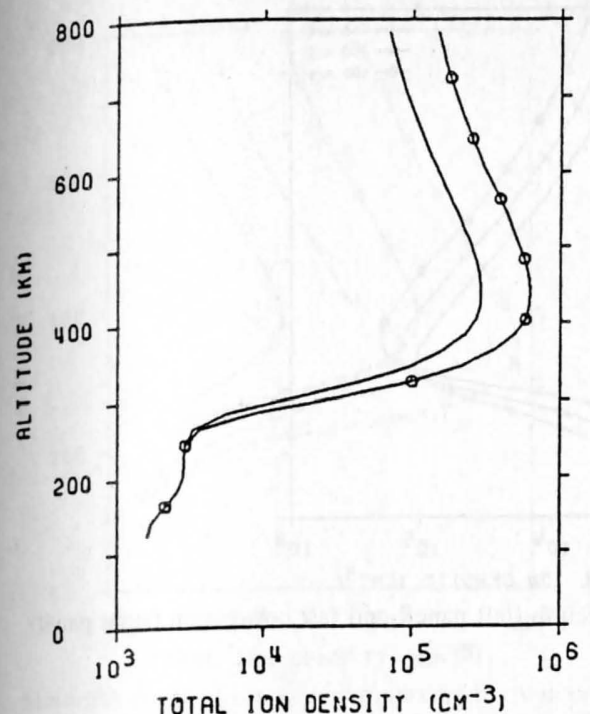

Fig. 7. Midnight $N_{e}$ profiles at solar maximum, equinox, for fast Fig. 7. line represents the case of a $160-\mathrm{m} / \mathrm{s}$ neutral wind on the dayside and an $800-\mathrm{m} / \mathrm{s}$ neutral wind on the nightside.

few hours [Sojka and Schunk, 1983]; therefore the fast convection midnight densities are comparable to their dayside values even though the location is far from the terminator (see Figure 2). As the neutral wind speed increases, the density decreases. This is due to the presence of a strong dayside wind causing downward ion drifts and resulting in lower $h_{m} F_{2}$ and $N_{m} F_{2}$ values on the dayside for winter conditions.

The solar maximum, summer, midnight $N_{e}$ density profiles are shown in Figure 4, with the slow and fast convection results displayed in the left and right panels, respectively. Again, the slow convection $h_{m} F_{2}$ values are larger than those for fast convection, and these summer $h_{m} F_{2}$ values are very similar to the winter values. The major difference from winter is that now the slow convection densities are comparable to the fast convection densities and for nonzero winds even exceed the densities for fast convection. Since the trajectories cross the summer terminator near the midnight meridian (see Figure 2), plasma decay is relatively unimportant. In addition, the wind-induced downward plasma drift on the dayside is ineffective, since the flux tube also enters regions of wind-induced upward drift while still in sunlight. These two effects combine to give an increasing $N_{m} F_{2}$ with neutral wind speed.

In Figure 5, contours of $\log _{10} N_{e}$ as a function of altitude and position along the summer slow trajectory highlight these competing $h_{m} F_{2}$ processes for the $400-\mathrm{m} / \mathrm{s}$ neutral wind case. The position axis corresponds to the markers placed on the slow trajectory in Figure 2 (left panel); the location marked with an $\mathrm{S}$ at the top of Figure 5 corresponds to the time when the plasma following the slow trajectory crossed the summer solar terminator. Also, the $\mathrm{M}$ indicates midnight, the location corresponding to the profile shown in Figure 4 (left panel). On the dayside the wind-induced downward drift causes the peak (dashed line, Figure 5) to have an $h_{m} F_{2}$ value $<300 \mathrm{~km}$ and a density $\simeq 4 \times 10^{5} \mathrm{~cm}^{-3}$. At midnight the peak is raised, $h_{m} F_{2} \sim 400 \mathrm{~km}$, and the density is increased to $\simeq 6 \times 10^{5} \mathrm{~cm}^{-3}$.

Figure 6 shows the solar maximum, equinox, midnight $N_{e}$ profiles for slow and fast convection. For the case of no neutral wind, the $F$ region peak is higher in altitude but lower in density for slow convection than for fast convection. This is similar to the winter case (Figure 3 ). In contrast, for a $400-\mathrm{m} / \mathrm{s}$ wind the $F$ region peak has both higher $h_{m} F_{2}$ and $N_{m} F_{2}$ values for slow convection than for fast convection. A comparison of Figures 3,4 , and 6 shows that the height of the $F$ layer increases with neutral wind speed and this increase is independent of the season. Thus, the height of the peak is effectively independent of whether or not the flux tube is in a region of high ion production, in this case day or night.

During the recent solar maximum period, improved in-situ neutral wind measurements were made by the Dynamics Explorer 2 satellite. These measurements have shown that in the magnetic polar regions, wind speeds in excess of $400 \mathrm{~m} / \mathrm{s}$ are common [Hays et al., 1984]. Furthermore, observations of wind speeds over 800 $\mathrm{m} / \mathrm{s}$ have also been made [Killeen et al., 1984]. The origin of these high wind speeds is associated with ion-neutral coupling in the dayside cusp region where very strong $\mathbf{E} \times \mathbf{B}$ ion drifts drive the neutral gas to high speeds as they mutually flow antisunward over the magnetic polar cap [Killeen et al., 1984; Hays et al., 1984]. In Figure 7, midnight $N_{e}$ profiles are shown for a high neutral wind speed, $800 \mathrm{~m} / \mathrm{s}$, and for solar maximum, equinox, and fast convection. The solid line corresponds to a symmetric day-night wind speed of $800 \mathrm{~m} / \mathrm{s}$, while the other profile corresponds to a reduced dayside wind speed of $160 \mathrm{~m} / \mathrm{s}$ and a nightside wind speed of $800 \mathrm{~m} / \mathrm{s}$. This latter case is a simple attempt to allow for the finite time and hence distance over which the ion-neutral coupling acts before the neutral wind speed reaches $800 \mathrm{~m} / \mathrm{s}$. Both profiles show
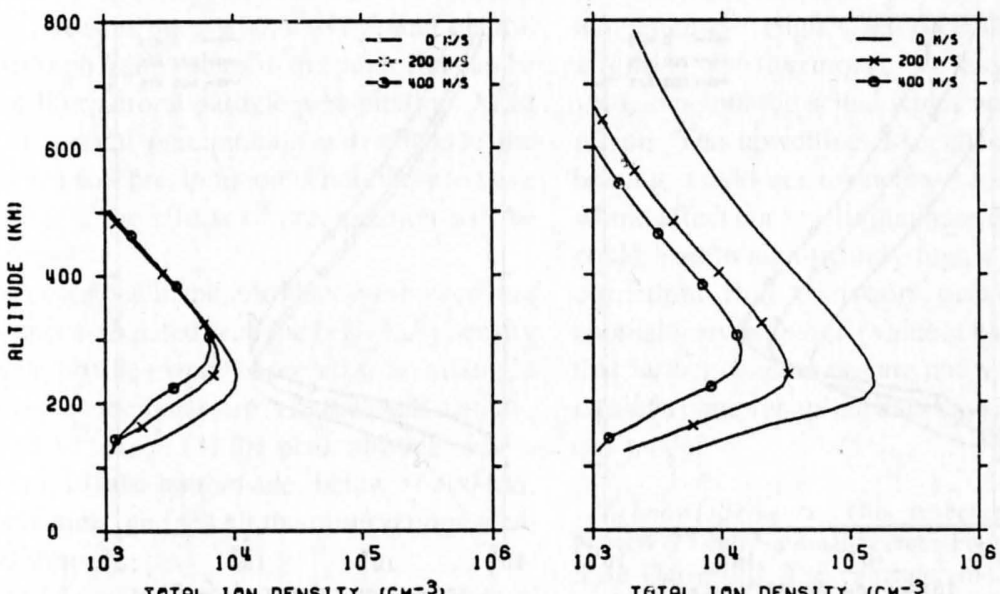

Fig. 8. Midnight $N_{e}$ profiles at solar minimum, winter, for slow convection (left panel) and fast convection (right panel). 

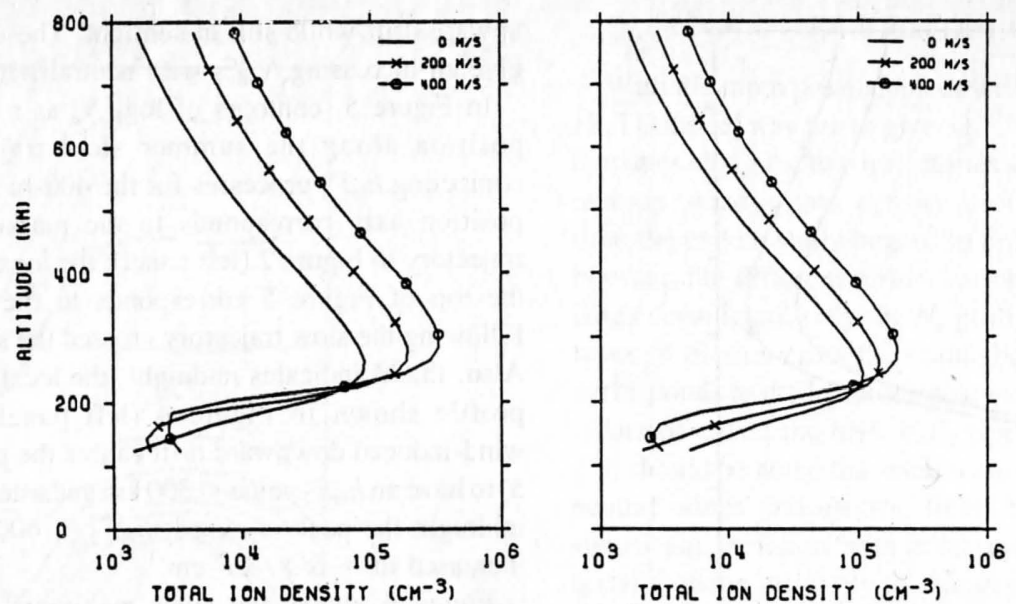

Fig. 9. Midnight $N_{e}$ profiles at solar minimum, summer, for slow convection (left panel) and fast convection (right panel).

$h_{m} F_{2}$ to be $\sim 440 \mathrm{~km}$. This corresponds to an increase of about 40 $\mathrm{km}$ from the solar maximum, equinox, fast convection case in Figure 6 (right panel). In Figure 7 , note that the bottomside ionosphere is depleted, a significant feature and one which is characteristic of the radar observations.

\section{Solar Minimum}

Figure 8 shows the midnight $N_{e}$ profiles for solar minimum, winter conditions and both slow convection (left panel) and fast convection (right panel). The height of the $F$ layer ranges from 220 to $280 \mathrm{~km}$. This range of altitudes for $h_{m} F_{2}$ is considerably lower than the equivalent solar maximum range of from 280 to $400 \mathrm{~km}$ (Figure 3) owing primarily to the different neutral atmospheres. The effect of the atmospheric change can be seen most clearly by comparing the slow convection, zero neutral wind cases in Figures 3 and 8 , because for these cases the induced vertical ion drift is negligible. This comparison indicates that the atmospheric change from solar maximum to solar minimum causes $h_{m} F_{2}$ to decrease by $80 \mathrm{~km}$, a result consistent with that found by Schunk and Raitt [1980] for daytime steady state conditions.

For both slow and fast convection the highest $h_{m} F_{2}$ occurs for the $400-\mathrm{m} / \mathrm{s}$ wind case. This neutral wind at solar minimum produces an $h_{m} F_{2}$ value of $280 \mathrm{~km}$. The solar minimum, winter $h_{m} F_{2}$ shows very little difference between the slow and fast convection cases (left and right panels of Figure 8). As was found for solar maximum, the slow convection $N_{m} F_{2}$ values are considerably lower than the fast convection values, and $N_{m} F_{2}$ decreases with increasing neutral wind speed. For slow convection the midnight $N_{m} F_{2}$ values are below $10^{4} \mathrm{~cm}^{-3}$.

The solar minimum summer and equinox midnight $N_{e}$ profiles are shown in Figures 9 and 10, respectively. For these cases, $h_{m} F_{2}$ varies from $220 \mathrm{~km}$ to a maximum of $300 \mathrm{~km}$. During summer conditions, both $N_{m} F_{2}$ and $h_{m} F_{2}$ increase with increasing neutral wind speed. However, these increased values are somewhat less than the corresponding solar maximum values. The summer and equinox trends for solar minimum are the same as those for solar maximum.

\section{Asymmetric Wind}

With the exception of Figure 7, all the cases shown were for neutral winds which had a constant speed along the 1300 to $0100 \mathrm{LT}$ meridian. For higher wind speeds, 200 and $400 \mathrm{~m} / \mathrm{s}$, this constant value on the dayside may well be an overestimate in some cases. These higher speeds are generated by ion-neutral coupling acting over the cusp-magnetic pole region. However, this coupling implies that the wind speed increases gradually over this region.
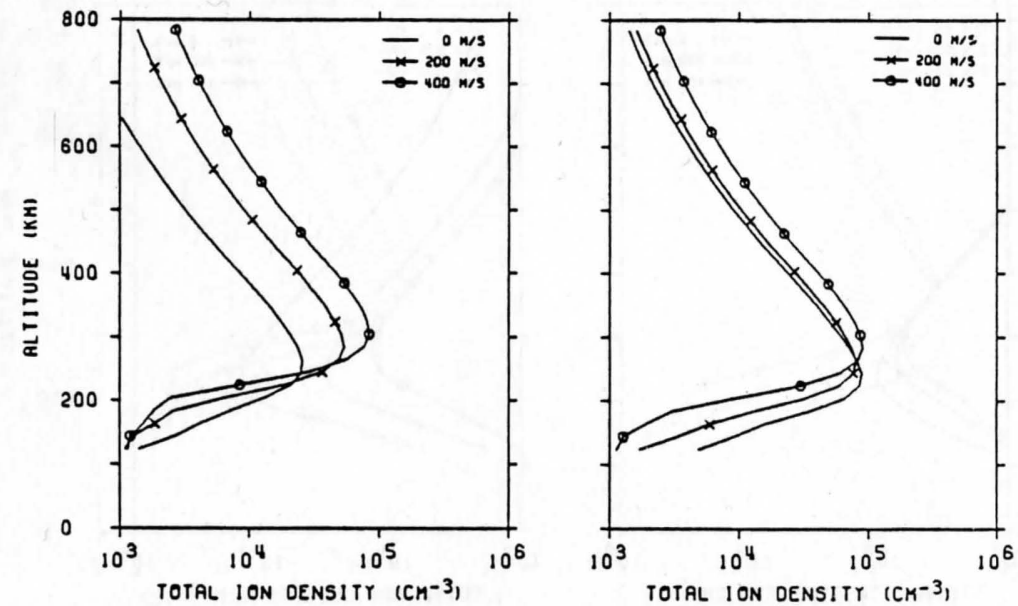

Fig. 10. Midnight $N_{e}$ profiles at solar minimum, equinox, for slow convection (left panel) and fast convection (right panel). 


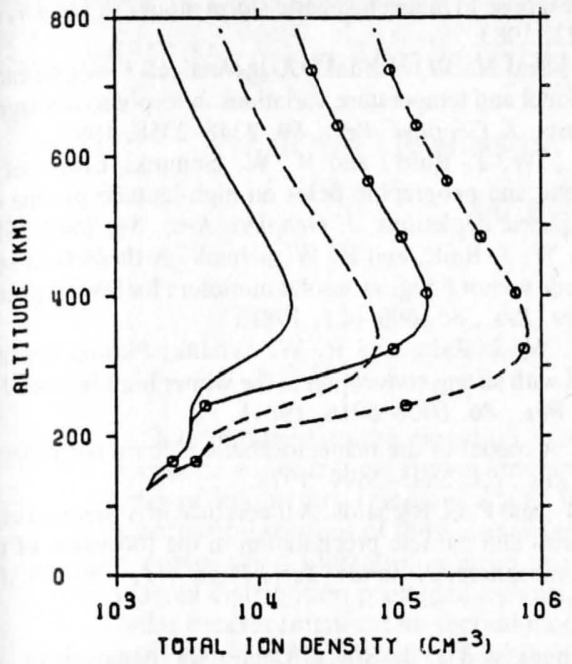

Fig. 11. Midnight $N_{e}$ profiles at solar maximum, winter, for slow convection (solid lines) and fast convection (dashed lines). The profiles without symbols are for a $400-\mathrm{m} / \mathrm{s}$ neutral wind, whereas the profiles with symbols are for the case when the downward wind-induced plasma drift on the dayside is inhibited.

Hence, the use of a constant, high-speed wind on the dayside may well overestimate the downward induced drift and, consequently, overestimate the lowering and decay of the $F$ region on the dayside. This would be most important under winter conditions where little solar EUV production is present in the polar cap.

To see how quantitatively significant this effect is, the solar maximum, winter, $400-\mathrm{m} / \mathrm{s}$ wind cases were repeated with the dayside neutral wind set to zero. Figure 11 contrasts the slow convection (solid lines) and fast convection (dashed lines) midnight $N_{e}$ profiles. The original $400-\mathrm{m} / \mathrm{s}$ profiles copied from Figure 3 have no symbols, while the profiles with circles represent the cases with no dayside neutral wind. Note that $h_{m} F_{2}$ remains unchanged, but that $N_{m} F_{2}$ increases by over an order of magnitude in both the slow and fast convection cases. For fast convection the peak density almost reaches $10^{6} \mathrm{~cm}^{-3}$ at $350 \mathrm{~km}$, while for slow convection the peak increases from less than $10^{4}$ to greater than $10^{5} \mathrm{~cm}^{-3}$ at an $h_{m} F_{2}$ of $400 \mathrm{~km}$. This highlights the importance of the plasma's history in determining the local $N_{e}$ values and to a much lesser extent the $h_{m} F_{2}$ value.

\section{SUMMARY}

The results of the HLTD model study of transport effects for a wide range of solar cycle, season, magnetic activity, and neutral wind conditions show that high $h_{m} F_{2}$ values in the polar cap can be generated without the need for auroral particle precipitation. Most certainly, the addition of auroral precipitation will enhance the $N_{m} F_{2}$ values. However, even soft precipitation is not likely to have an appreciable effect on $h_{m} F_{2}$; the effects of precipitation will be discussed in a separate paper.

The radar observations described in the introduction showed that there were five main features associated with the high $h_{m} F_{2}$ density profiles, namely, (1) these profiles were observed near midnight with the plasma flowing out of the polar cap, (2) the peak density, $N_{m} F_{2}$, ranged from $10^{5}$ to $10^{6} \mathrm{~cm}^{-3}$, (3) the peak altitude, $h_{m} F_{2}$, ranged from 400 to $500 \mathrm{~km},(4)$ the bottomside, below $\simeq 300 \mathrm{~km}$, was almost devoid of ionization, and (5) all the observations were for solar maximum conditions.

The solar maximum model results show that for neutral winds of greater than $400 \mathrm{~m} / \mathrm{s}$, and especially for $800 \mathrm{~m} / \mathrm{s}$, items 1 to 4 in the above list were obtained. During winter conditions the value of $N_{m} F_{2}$ at midnight depends initially on the neutral wind-induced downward ion drift in the dayside polar cap. This dependence produces over an order of magnitude difference in the midnight $N_{m} F_{2}$ value. For equinox and summer conditions this dependence is much weaker because the wind-induced downward drift occurs in sunlit regions, and hence, $N_{m} F_{2}$ does not substantially decay.

In addition to this very specific comparison with the anomalously high $h_{m} F_{2}$ observations, our study reveals other general results for the influence of transport in the polar ionosphere:

1. The solar minimum midnight $h_{m} F_{2}$ values are typically 70 to $100 \mathrm{~km}$ lower than the solar maximum values for similar seasonal, magnetic activity, and neutral wind conditions. In addition, the solar minimum midnight $N_{m} F_{2}$ values can be up to an order of magnitude lower in winter and about a factor of 2 lower in summer than at solar maximum.

2. During winter conditions the effect of an increased neutral wind speed is to increase $h_{m} F_{2}$ and to decrease $N_{m} F_{2}$ for transpolar plasma transport. The density reduction is associated with a dark dayside region of downward wind-induced drift which causes the ionosphere to rapidly decay.

3. For summer and equinox conditions the effect of increasing the neutral wind is to increase both $h_{m} F_{2}$ and $N_{m} F_{2}$.

4. Magnetic activity affects each season differently. During winter, fast convection across the polar cap yields densities up to an order of magnitude higher than for slow convection. This results because both trajectories are in darkness, and hence, the slower convecting plasma has more time to decay. For equinox and especially summer conditions this trend is almost reversed. The slow convection in combination with an upward wind-induced drift builds up the $F$ layer in a region that is still sunlit, to values comparable to or larger than the fast convection case.

These results have been shown for a single flux tube exiting the polar cap around midnight. The same results apply to the majority of plasma flux tubes which are convected antisunward over the polar cap and exit in the region of \pm 3 hours about midnight.

Our model studies indicate that transport effects at solar maximum can easily produce $h_{m} F_{2}$ values between 400 and $440 \mathrm{~km}$. However, it should be noted that even though these results were based on a large number of simulations, our model was simplistic and many more simulations could have been done. For example, we considered only two convection trajectories, and other trajectories could produce higher $h_{m} F_{2}$ values for a given geophysical situation. Also, only one set of nocturnal electron and ion temperature profiles was adopted, and these profiles were characterized by fairly low temperatures. Higher temperatures would act to increase $h_{m} F_{2}$ slightly. Furthermore, we assumed generally steady wind velocities, but the actual winds are highly variable in the polar cap region. The upwelling associated with variable winds and Joule heating would act to increase $h_{m} F_{2}$. None of these mechanisms would affect our results qualitatively, but in the proper combination could lead to significantly higher $h_{m} F_{2}$ values. Therefore, we are confident that transport processes alone can explain the anomalously high $h_{m} F_{2}$ values observed by the radars. We also feel that further calculations are not warranted at this time owing to the lack of a comprehensive data base of the input parameters needed by our model.

Acknowledgments. This research was supported by NASA grant NAGW-77 and National Science Foundation grant ATM-8217138 to Utah State University. The computer modeling effort was supported by the National Center for Atmospheric Research, which is sponsored by the National Science Foundation. 
The Editor thanks T. J. Fuller-Rowell and another referee for their assistance in evaluating this paper.

\section{REFERENCES}

Banks, P. M., and G. Kockarts, Aeronomy, Academic, New York, 1973. Hays, P. B., T. L. Killeen, N. W. Spencer, L. E. Wharton, R. G. Roble, B. A. Emery, T. J. Fuller-Rowell, D. Rees, L. A. Frank, and J. D. Craven, Observations of the dynamics of the polar thermosphere, J. Geophys. Res., 89, 5597-5612, 1984.

Hedin, A. E., C. A. Reber, G. P. Newton, N. W. Spencer, H. C. Brinton, H. G. Mayr, and W. E. Potter, A global thermospheric model based on mass spectrometer and incoherent scatter data, MSIS2, Composition, $J$. Geophys. Res., 82, 2148, 1977.

Killeen, T. L., P. B. Hays, C. R. Carigan, R. A. Heelis, W. B. Hanson, N. W. Spencer, and L. H. Brace, Ion-neutral coupling in the high-latitude $F$ region: Evaluation of ion heating terms from Dynamics Explorer 2, J. Geophys. Res., 89, 7495-7508, 1984.

Murdin, J., J. J. Sojka, and R. W. Schunk, Diurnal transport effects on the $F$-region plasma at Chatanika under quiet and disturbed conditions, Planet. Space Sci., 32, 47-61, 1984.

Murphy, J. A., G. L. Bailey, and R. J. Moffet, Calculated daily variations of $\mathrm{O}^{+}$and $\mathrm{H}^{+}$at mid-latitudes, J. Atmos. Terr. Phys., 38, 351-364, 1976.

Schunk, R. W., and W. J. Raitt, Atomic nitrogen and oxygen ions in the daytime high-latitude $F$ region, J. Geophys. Res., 85, 1255-1272, 1980. Sojka, J. J., and R. W. Schunk, A theoretical study of the high latitude $F$ region's response to magnetospheric storm inputs, J. Geophys. Res..d.
$2112-2122,1983$.

Sojka, J. J., and R. W. Schunk, A theoretical $F$ region compositional and temperature variations in response to mady of storm inputs, J. Geophys. Res., 89, 2348-2358, 1984 magnetont of

Sojka, J. J., W. J. Raitt, and R. W. Schunk, 1984 geomagnetic and geographic poles on high-latitude plect of displ and ionospheric depletions, J. Geophys. Res., 84, 5943 convecter Sojka, J. J., W. J. Raitt, and R. W. Schunk, A theoretical 595 , 1979 high-latitude winter $F$ region at solar minimum for low mal study of J. Geophys. Res., 86, 609-621, 1981a.

Sojka, J. J., W. J. Raitt, and R. W. Schunk, Plasma densty associated with strong convection in the winter high-latitusity fe Geophys. Res., 86, 6908-6916, 1981 b.

Volland, H., A model of the magnetospheric electric convection fielt Geophys. Res., 83, 2695-2699, 1978.

Watkins, B. J., and P. G. Richards, A theoretical investigation of the neutral winds and particle precipitation in the formation of the roke of F-region ionosphere, J. Atmos. Terr. Phys., 41, 179-189, 1979

R. W. Schunk and J. J. Sojka, Center for Atmospheric and Space
ciences, Utah State University, Logan, UT 84322 .

(Received November 26, 1984; revised February 12, 1985; accepted February 18, 1985.) 